This is an electronic reprint of the original article. This reprint may differ from the original in pagination and typographic detail.

Author(s): Rintala, Pauli; Temple, Viviene A.; Lloyd, Meghann; Faro, Chris; Foley, John T.

Title: $\quad$ Association of poverty and social exclusion with Body Mass Index among Special Olympics athletes in Europe

Year: $\quad 2017$

Version:

Please cite the original version:

Rintala, P., Temple, V. A., Lloyd, M., Faro, C., \& Foley, J. T. (2017). Association of poverty and social exclusion with Body Mass Index among Special Olympics athletes in Europe. International Journal of Public Health, 62(8), 921-928.

https://doi.org/10.1007/s00038-017-0982-5

All material supplied via JYX is protected by copyright and other intellectual property rights, and duplication or sale of all or part of any of the repository collections is not permitted, except that material may be duplicated by you for your research use or educational purposes in electronic or print form. You must obtain permission for any other use. Electronic or print copies may not be offered, whether for sale or otherwise to anyone who is not an authorised user. 


\section{Association of poverty and social exclusion with Body Mass Index among Special Olympics} athletes in Europe

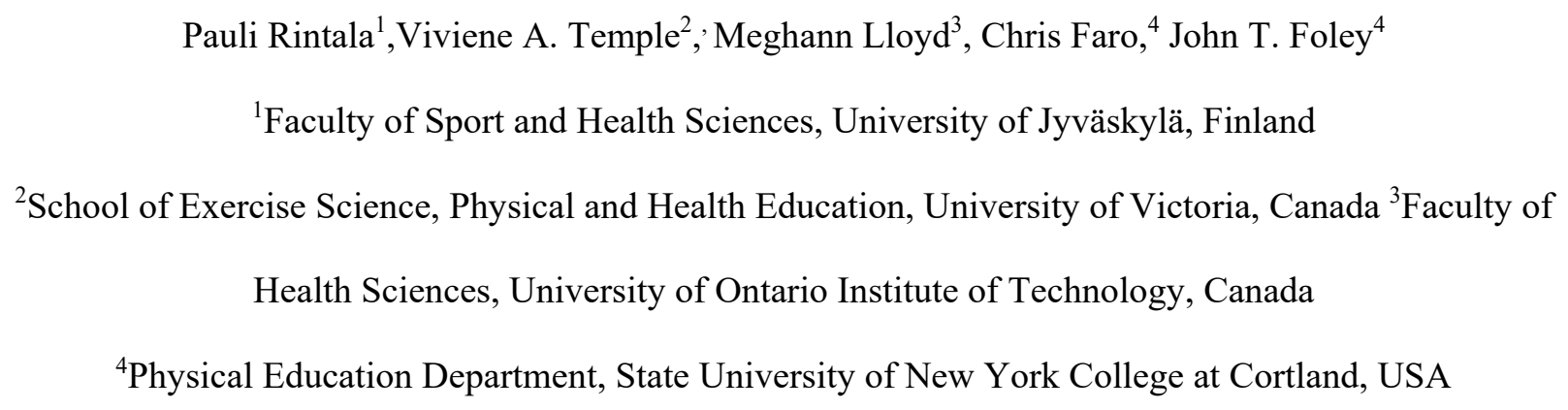

Objectives: To examine the association of a risk of poverty and social exclusion (AROPE), age, and gender with the Body Mass Index (BMI) status of European Special Olympics athletes.

Methods: BMI records were available for 1,905 children and youth and 5,517 adults from the Special Olympics International (SOI) Health Promotion database. AROPE was extracted from EU Eurostat statistics. Logistic regression analyses were used to predict BMI status.

Results: For children/youth and adults respectively, $9.4 \%$ and $6.3 \%$ were underweight and $25.3 \%$ and $44.6 \%$ were overweight/obese. Being underweight was significantly associated with higher AROPE rates. Being female, and lower AROPE rates, were significantly associated with overweight/obesity for both children/youth $(\mathrm{OR}=1.27 ; 95 \% \mathrm{CI}: 1.07-1.50$ and $\mathrm{OR}=0.97 ; 95 \% \mathrm{CI}: 0.96-0.98)$ and adults $(\mathrm{OR}=1.55 ; 95 \%$ CI: $1.39-1.72$ and $\mathrm{OR}=0.96 ; 95 \%$ CI: 0.95-0.98).

Conclusions: The Europe 2020 "platform against poverty" strategy aims to ensure that those experiencing poverty and social exclusion share the benefits of economic growth. These findings suggest that SOI health promotion efforts to foster healthy BMI is needed and should be tailored to specific social and economic circumstances in Europe. 
Poverty and social exclusion and weight status

26 Keywords: intellectual disability; underweight; overweight; Special Olympics; Body Mass Index;

27 poverty and social exclusion

28 
Poverty and social exclusion and weight status

\section{Introduction}

A flagship initiative of the Europe 2020 strategy is the "European platform against poverty" (European Commission 2010, p.6). The initiative aims to reduce the number of people living in poverty by $25 \%$ by 2020, and to enable them to "live in dignity and take an active part in society" (European Commission 2010, p.19). To that end, the European Commission annually monitors indicators of poverty and social exclusion (Eurostat 2016a). In 2014, 24.4\% of the entire EU population and $27.8 \%$ of EU children lived in households experiencing poverty or social exclusion (AROPE) (Eurostat 2016a). AROPE is defined in the Europe 2020 strategy as the proportion of the population experiencing at least one of the following conditions: at risk for monetary poverty, severe material deprivation, or living in a household with a very low work intensity (Eurostat 2016c). What is unknown from these statistics is how European individuals with an intellectual disability (ID) are impacted in terms of their health.

Intellectual disability

Intellectual disability (ID) is a disability characterised by significant limitations in intellectual functioning and adaptive behaviour, with onset occurring in the person's developmental years (Schalock 2011). ID is a multidimensional state of human functioning and affects a person's everyday life. Compared with people without an ID, individuals with an ID are socially vulnerable (McGrath et al. 2010), experience lower quality of life (Nota et al. 2007), have high rates of mental health concerns (Bigby 2012), and they are less self-determined (Nota et al. 2007). Overall, the international literature suggests that they are a vulnerable population that exists on the peripheries of society (Emerson 2007). Poverty and ID are often present concurrently, and Emerson (2007) suggests that this association reflects two distinct processes. First, poverty causes ID because those living in poverty are exposed to environmental and psychosocial hazards such as poor nutrition and housing or environmental toxin. Second, individuals with an ID and their families experience poverty because people with ID are often 
Poverty and social exclusion and weight status

54 excluded from the workforce and those caring for individuals with ID often assume additional financial 55 and social responsibilities (Emerson 2007). Emerson also notes that the association between poverty and 56 ID “...accounts in part for the health and social inequalities experienced by people with intellectual 57 disabilities and their families" (Emerson 2007, p.107). Therefore it might be expected that as a result of 58 their increased risk of exposure to poverty, people with ID will have poorer health and greater rates of 59 social exclusion than their peers without ID.

Overweight and obesity of individuals with ID in Europe

62

Adults with ID in countries of the EU generally have high rates of overweight and obesity, particularly among women (Bhaumik et al. 2008; Gazizova et al. 2012; Melville et al. 2008). However, the vast majority of studies showing this trend have been drawn from samples in the United Kingdom (Bhaumik et al. 2008; Gazizova et al. 2012; Melville et al. 2008). Evidence from other EU countries is limited. Smaller samples $(n=38)$ from Spain (Soler Marín and Xandri Graupera 2011) and $(n=129)$ from Sweden (Bergström et al. 2013) and a larger sample $(n=945)$ of older adults with an ID from the Netherlands (de Winter et al. 2012), show rates of obesity that are consistent with the findings from the UK. These trends are a concern, since high BMI levels place individuals with ID at greater risk for hypertension (Bhaumik et al. 2008; Sohler et al. 2009), hypercholesterolemia (Sohler et al. 2009), high serum triglycerides (Gazizova et al. 2012), Type 2 diabetes (Sohler et al. 2009), and the metabolic syndrome in general (Hsu et al. 2012).

There is limited research on the rates of obesity in children and youth with ID in the EU. Lloyd et al. (2012) studied worldwide obesity rates in Special Olympics participants, and found in a sample of 1,137 children and youth participating in Special Olympics from Europe/Eurasia ( $n=749$ boys), that $21.9 \%$ of the boys and $30.9 \%$ of the girls were overweight or obese. However, the sample from Lloyd et al.'s study included many Eurasian countries not in the EU; therefore it is difficult to generalize these 
Poverty and social exclusion and weight status

79

80

81

82

83

84

85

86

87

88

89

90

91

92

93

94

95

96

97

98

99

100

101

102

103

BMI findings to the EU. Country specific studies have also reported high rates of overweight and obesity; for example a study $(n=1,120)$ in France demonstrated that $21.7 \%$ of the children with an ID were overweight and an additional 10.1\% were obese (Begarie et al. 2013). These authors also found that $19 \%$ of youth with ID were classified as overweight and a further $7.2 \%$ were obese. Despite these data from one high-income country, the general picture of overweight/obesity rates among children and youth with ID in the EU is unclear.

Underweight among individuals with ID in Europe

The rates of underweight $(\mathrm{BMI} \leq 18.5)$ among adults with an ID in Europe range widely. In the UK, when measured directly, the rates of underweight appear to range from 5-6\% (Melville et al. 2008) to 18.6\% (Bhaumik et al. 2008). However, Bhaumik et al. reported that the high rate of underweight was associated with having profound ID, although these authors did not report the proportion of their sample with profound ID. Excluding the very high rates of underweight reported by Bhaumik and colleagues (2008), in general, rates of underweight among individuals with ID seem to be lower in EU countries outside of the UK. In Spain, Soler Marin and Xandri Graupera (2011) found that 0\% of women and 4.3\% of men with Down syndrome were underweight, and Bergström et al. (2013) found that $2.4 \%$ of their sample 63 Swedish adults with ID were underweight. Where studies in the EU have reported the underweight status of men and women separately, men have higher rates of underweight (Bhaumik et al. 2008; Melville et al. 2008; Soler Marín and Xandri Graupera 2011). Although evidence of morbidity and mortality of underweight adults with an ID is not evident in the literature, underweight is associated with an increased risk of respiratory disease and infection (Prospective Studies Collaboration 2009) as well as hospitalization and all-cause mortality (Weitoft et al. 2008) in the general population.

Evidence related to rates of underweight in children and youth with ID is extremely limited. A study from Turkey $(n=70)$ found $5.4 \%$ of children and youth with ID were underweight (Sari and 
Poverty and social exclusion and weight status

104 Bahceci 2012) and another study from Denmark $(n=117)$ on children and youth with autism spectrum

105 disorder found $31 \%$ of males and $12 \%$ of females were below the $10^{\text {th }}$ BMI percentile (Mouridsen et al. 106 2002).

107

108

Disability and poverty

109

110 Disability, poverty, and social exclusion seem to be causally related, but the extent and significance of

111 the causal links between disability and poverty is expected to vary across disability types and across

112 communities (Braithwaite and Mont 2009). However, very little comparative quantitative research has

113 been undertaken (Braithwaite and Mont 2009). The impact of country economic status, specifically on

114 the BMI amongst individuals with an ID, has been examined in two recent studies using the Special

115 Olympics Healthy Athletes database; one paper focusing on children (Lloyd et al. 2014) and one

116 focusing adults (Temple et al. 2015). These related studies used The World Bank's classification of

117 country economic status to examine BMI among Special Olympics participants from 159 countries.

118 Among almost 20,000 adults, Temple et al. (2015) found that the rate of underweight was high in low-

119 income countries (17.2\%), still relatively high in upper-middle income and low middle-income countries

120 (10.8\% and 9.6\%, respectively), and lowest in high-income countries (4.6\%). Whereas obesity rose from

$1214.2 \%$ in low-income countries to $34.1 \%$ in high-income countries; however there were significant sex-

122 based differences with women more likely to be obese at every level of economy. Lloyd et al. (2014)

123 found, in a sample of 14,032 children and youth, that the proportion who were underweight was: $10.0 \%$

124 in low-income countries, $2.0 \%$ in low-middle income countries, $3.2 \%$ in upper-middle income countries,

125 and $2.7 \%$ in high income countries. These data indicate that the rates of underweight of children and

126 youth with ID were higher than the rates published for children and youth with non-ID groups in the

127 same economic status (Lloyd et al. 2014). Lloyd and colleagues (2014) found the prevalence of

128 overweight and obesity, respectively were: $14.8 \%$ and $3.1 \%$ in low income countries, $23.6 \%$ and $5.4 \%$ in 
Poverty and social exclusion and weight status

129 low-middle income countries; $15.9 \%$ and $6.2 \%$ in upper-middle income countries, and $21.6 \%$ and $18.0 \%$

130 in high income countries. These broad world trends in BMI status of adults and children with an ID

131 based on macro-level indicators have not been examined in regional samples. The aim of the current

132 study was to report the rates of underweight and overweight/obesity of children and youth, and adult

133 Special Olympics participants in the EU. In addition, we investigated the extent to which age, risk of

134 poverty, and social exclusion (measured by AROPE), and gender predicted rates of underweight and

135 overweight/obesity to better understand how personal and socio-economic variables impact on BMI

136 status in this sample of Special Olympics participants from the EU.

\section{Methods}

139 Data source

140 Special Olympics is a global not-for-profit sporting organization serving approximately 5 million people

141 with ID around the world (Special Olympics 2016). Special Olympics has programs in over 170

142 countries and offers free health screenings at local, State/Provincial, National, and World Games. Data

143 from the health screenings are entered into Special Olympics databases. Before participation in all

144 Special Olympics events, athletes and/or their guardians sign a medical release/consent form to

145 participate in their respective event(s). As part of this document, separate consent is given for the

146 participation in Healthy Athletes screenings which includes consent for the de-identified data to be used

147 to report on the health of Special Olympics athletes. Currently Special Olympics is the largest single

148 source of international health surveillance data and health services for people with ID in the world

149 (Special Olympics 2016). For the present study, Special Olympics provided access to the following

150 variables from their Health Promotion database: gender, age, event, location, delegation (specifically 28

151 EU-countries and three European Free Trade Association (EFTA) countries), height, and weight. The

152 AROPE rate for each of these EU-28 and EFTA countries was obtained from Eurostat (Eurostat 2016a).

153 The AROPE rate represents the proportion of the population experiencing monetary poverty, severe 
Poverty and social exclusion and weight status

154 material deprivation, or very low work intensity (Eurostat 2016b). Height and weight were assessed

155 directly by trained personnel at Special Olympics events using protocols developed by Special Olympics

156 (2007). Weight was measured to $0.1 \mathrm{~kg}$ using digital scales and height was measured to the nearest $0.1 \mathrm{~cm}$ 157 using portable stadiometers. Ethics approval for this secondary analysis was provided by the institutional 158 ethics review committee of each author's university.

159

160 Data cleaning and analyses

161

162 The initial data of 8,506 available entries for both children/youth aged 8-17 years old and adults aged 1816365 years old from 2006-2013 were examined and filtered to remove extreme or missing values. This

164 methodology for data cleaning was based off previous studies using the Special Olympics database

165 (Temple et al. 2015). The values for inclusion of adults were height between $121.9 \mathrm{~cm}$ and $238.8 \mathrm{~cm}$ and

166 weight between $30.0 \mathrm{~kg}$ and $317.5 \mathrm{~kg}$ as identified in previous work (ALSWH 2007). For children/youth,

167 height and weight values between $+/-5 \mathrm{z}$ score as identified using the ZANTHRO macro for Stata were

168 retained (Vidmar et al. 2004).

Listwise deletions were used when anthropometric, gender, age, or country data were missing or determined to be extreme; total number of cases excluded were 1099 (13\%). Data from the EU-28 and

171 EFTA countries in the Eurostat database were extracted on February 16, 2016. The AROPE rate data for each of the participant's home country were matched to the participants' event year (year in which the

173 SO event took place) that the healthy athlete data was collected. To increase the sensitivity of the 174 analysis, subgroup values from Eurostat were used. These subgroup data provide a specific AROPE rate 175 value for gender and the following age groups: $<16 \mathrm{y}, 16-24 \mathrm{y}, 25-54 \mathrm{y}$, and $>54 \mathrm{y}$. 
Poverty and social exclusion and weight status

179 World Health Organization (1995) cut-points: Underweight $<18.5$, Normal range 18.5-24.9, Overweight

180

181

182

183

184

185

186

187

188

189

190

191

192

193

194

195

196

197

198

199

200

201

202 25.0-29.9, and Obese $\geq 30$ were applied.

A series of multiple logistic regressions were run to examine how the following model with three predictor variables: gender (as a dichotomous variable; male $=0$, female $=1$ ), age (as a continuous variable), and AROPE rate (as a continuous variable) were associated with the likelihood (i.e. Odds

Ratio, OR) of being in a given weight status (underweight - not underweight or overweight/obese - not overweight/obese). An OR is an indicator of the probability of a condition such as overweight/obesity resulting from a unit change in a predictor e.g. age (Persoskie and Ferrer 2017). As such, and as an example, a significant association between age and rate of overweight/obesity (e.g. $\mathrm{OR}=1.04)$ means that for every 1 year increase in age the odds of being overweight are increased by approximately $4 \%$. To adjust for the lack of independence associated with clustering by country a robust estimator of variance was used with a clustering option. These analyses were performed for children and adults separately. Data were analyzed using STATA/MP Version 12 for windows (StataCorp LP, College Station, TX).

\section{Results}

A total of 7,422 (1,905 children/youth and 5,517 adults) Special Olympics participant BMI records were available. Of the child/youth sample 173 were children $<12$ years of age and 1,732 were $12-18$ years of age. Mean age, height, and weight as well as the proportion of children/youth and adults in each BMI category are presented in Table 1. Table 2 shows that a higher AROPE rate (higher risk of poverty and social exclusion) was significantly associated with higher rates of underweight for children/youth and adults $(\mathrm{OR}=1.03$ and $\mathrm{OR}=1.04$, respectively $)$. In addition, being older $(\mathrm{OR}=1.06)$ and male $(\mathrm{OR}=$ 0.82) was associated with higher rates of underweight among children/youth; and being younger was associated with higher rates of underweight among adults $(\mathrm{OR}=0.94)$. Lower AROPE rates and being 
Poverty and social exclusion and weight status

203 female were significant predictors of overweight/obesity for both children/youth and adults (see Table 2).

204 Further, among adults, rates of overweight/obesity were higher with increasing age (OR = 1.04).

205

\section{Discussion}

207 The aim of this study was was to report the rates of underweight and overweight/obesity of children and

208 youth, and adult Special Olympics participants in the EU, and to examine the association of AROPE rate 209 with the BMI status of European Special Olympics participants. Results indicate that the rates of

210 underweight, overweight and obesity in European Special Olympics participants were higher than would

211 be expected in the general population. Our findings also indicate that the risk of poverty and social

212 exclusion (high AROPE rate) is associated with the BMI status (underweight and overweight/obese) of

213 both children and adults with ID who participate in Special Olympics in the EU.

215 Prevalence of underweight

Among the adults, rates of underweight were relatively consistent between males and females. This rate of approximately $6 \%$ was higher than previously found among adult Special Olympics athletes from Europe/Eurasia (i.e. around 4.5\%); but similar to other studies of adults with ID in European countries where BMI has been directly measured (Gazizova et al. 2012; Melville et al. 2008). In our data there was that $82 \%$ of the adults who were underweight came from four countries, and more than half of those came from one country. That particular country had one of the highest AROPE rates in 2010 indicating an extreme risk of poverty and social exclusion for the entire country (Antufermo and Di Meglio 2012).

224 Our results indicate that individuals with ID are at high risk of being underweight when the AROPE rate 225 is high; and being underweight is a significant predictor of health. Although an overall underweight 226 prevalence of $6 \%$ at the population level is a relatively low prevalence from a public health perspective 227 (World Health Organization 1995), there were countries with higher overall rates of underweight, which 
Poverty and social exclusion and weight status

228

229

230

231

232

233

234

235

236

237

238

239

240

241

242

243

244

245

246

247

248

249

250

251

252

suggests closer monitoring is needed. At an individual level, Special Olympics suggests that athletes considered underweight should be referred to a health professional, however the extent to which this referral is followed up by the individual, their family, or care-providers is unknown.

The underweight rate for children/youth was quite high at 9.4\% in our study. Although many of the underweight children/youth in this study were from countries with high rates of poverty and social exclusion, this was not universally the case. Underweight was also evident in countries with low poverty rates. Being underweight is a significant indicator of poor health in children and in adults (Black et al. 2003; Prospective Studies Collaboration 2009; Weitoft et al. 2008); and therefore, further surveillance is needed to verify these findings and health promotion efforts are needed to identify the aetiology of the underweight status in children and how to prevent it.

Prevalence of overweight and obesity

The proportion of overweight/obese adults in the present study was very similar to the proportion identified as being overweight/obese in a Special Olympics sample from Europe/Eurasia (Temple et al. 2013). However, the rates of overweight/obesity in our study were lower than rates of overweight/obesity among adults with ID in Sweden (69.9\%) (Bergström et al. 2013), older adults with ID in the Netherlands $($ males $=52.9 \%$; females $=75.1 \%)($ de Winter et al. 2012), and adults with ID in the United Kingdom (Melville et al. 2008). It is perhaps not surprising that our rates were lower than for individuals with ID in the United Kingdom, since in the general population, the United Kingdom has the third highest rate of excess weight in Western Europe (Ng et al. 2014). Furthermore, our sample was considerably younger than the de Winter et al. sample, and as the odds of being overweight/obese increase with age (Temple et al., 2014), lower rates of overweight and obesity seem sensible. However, as the living circumstances of participants in this study are not known, it is unclear why the rate of overweight/obesity was lower in the present study than the rate reported for those living semi- 
Poverty and social exclusion and weight status

253 independently in Sweden (Bergström et al. 2013). Even though the rates of overweight/obesity in this

254 study were lower than in many previous studies, these rates were still high which is indicative of poor 255 health.

256 The combined overweight/obesity rate of children/youth in this study was $25.3 \%$, with females 257 having significantly higher rates than males. Given that $90 \%$ of the children/youth in the present study 258 were 12 years of age or older, our findings suggest that more than a quarter of adolescents with ID 259 participating in Special Olympics in the EU are overweight/obese. This is particularly troubling since 260 childhood obesity status moderately predicts adult obesity status, and the persistence of obesity from 261 adolescence to adulthood is high (Simmonds et al. 2015). Research to elucidate factors contributing to 262 these high rates of obesity in young people with ID is urgently needed. This research needs to extend 263 beyond calorie input and output to include other known contributing factors such as the adequacy of 264 sleep, the impact of medications, syndrome specific factors, as well as key aspects of the child/youth's 265 social and cultural environment, for example: food as rewards, family socio-economic status, and foods 266 available at home and at school (Harrison et al. 2011).

Risk for poverty and limitations of the study

Higher rates of AROPE, defined in this study as higher risk of monetary poverty, material deprivation, or low work-intensity (Eurostat 2016c), was significantly associated with higher rates of underweight for children and adults. This means that for individuals with ID who are at high risk of poverty and social exclusion, the risk of being underweight is also elevated. These findings are consistent with findings for children (Lloyd et al. 2014) and adults (Temple et al. 2015) with ID in global samples stratified by country economic status. For adult European Special Olympics participants, being younger and from a country with higher rates of AROPE were associated with higher rates of underweight. However, underweight was a more pervasive problem among children than adults in this sample, particularly 
Poverty and social exclusion and weight status

among boys. These underweight rates are higher than previously reported rates for children and youth with ID in the region (Mouridsen et al. 2002; Sari and Bahceci 2012). Lower AROPE, defined in this study as lower risk of monetary poverty, material deprivation, or low work-intensity, was significantly associated with overweight/obesity for both children and adult Special Olympics participants. In other words, the lower the risk of poverty and social exclusion, the higher the rates of overweight and obesity in this sample. Again, these findings are consistent with data derived from global samples by Lloyd et al. (2014) for children and Temple et al. (2015) for adults, where the high-income countries had the highest proportion of overweight/obese participants and the low-income countries had the lowest proportion. In addition to lower risk of poverty and social exclusion predicting overweight/obesity, being a female Special Olympics athlete in our study was significantly associated with higher rates of overweight/obesity; especially for adult athletes. This is also consistent with previous evidence that children and adult female Special Olympics athletes from Europe/Eurasia (Lloyd et al. 2012; Temple et al. 2013) and from high-income countries (Lloyd et al. 2014; Temple et al. 2015), have higher rates of overweight/obesity than males.

The results of the present study show that higher poverty and social exclusion scores were associated with high rates of underweight, while conversely, lower poverty and social exclusion scores were associated with high rates of overweight/obesity among child and adult Special Olympics athletes in Europe. As there are adverse health outcomes associated with both high rates of underweight and with high rates of overweight/obesity (Prospective Studies Collaboration 2009), our findings reveal that Special Olympics athletes living in European countries with both high and low rates of poverty and social exclusion are at risk of poor health based on adverse BMI profiles. Further investigation into the living circumstance of Special Olympics athletes in Europe is warranted, including the availability of, and access to: appropriate nutrition, health promotion efforts, as well as health care and surveillance. Special Olympics could also play a role in promoting healthy body weight among 
Poverty and social exclusion and weight status

302

303

304

305

306

307

308

309

310

311

312

313

314

315

316

317

318

319

320

321

322

323

324

325

athletes by increasing their health promotion efforts and support, particularly in countries with high AROPE rates to mitigate the adverse effects of poverty and social exclusion on BMI status.

A limitation of our study is that we know the AROPE rate of each athlete's country but we do not know the personal economic status of each individual. It is possible that individuals with ID in low AROPE rate countries are also at risk of living in poverty and being socially excluded. In addition, although we mention that several countries have especially high AROPE rates and associated high levels of underweight and overweight/obesity, based on our data sharing agreement with SOI we are not allowed to name the specific country/ies. Further, we do not know the etiology of ID, medication use, athletes' living arrangements, associated health conditions and the like, because these are not part of the database, and therefore association/s to AROPE could not be examined. However, this does not detract from the general trends we found showing that high levels of poverty and social exclusion were associated with poorer BMI status and by extension increased risk of poor health.

A final limitation of this study is the fact that all the participants were Special Olympics participants limiting the generalizability of the results. It is possible that because all the participants in this sample were competing at local, national and international sporting events that they were more physically active than their peers with ID who do not regularly participate in Special Olympics.

Therefore, our results may in fact underestimate the health concerns of people with ID. However, Special Olympics is an international organization with extensive reach and this is the largest global dataset on the health of individuals with ID. The results are further bolstered by the fact that height and weight are directly measured by trained professionals. More research is needed on a wider spectrum of participants with ID to understand if these results are generalizable. 
Poverty and social exclusion and weight status

326 All procedures performed in the study were in accordance with the ethical standards of the institutional

327 research committees of each participating university. (In order of authorship: University of Jyväskylä,

328 University of Victoria, University of Ontario Institute of Technology, and State University of New York

329 College at Cortland.) 
Poverty and social exclusion and weight status

331

332

333

334

335

336

337

338

339

340

341

342

343

344

345

346

347

348

349

350

351

352

353

\section{References}

ALSWH (2007) ALSWH Data Dictionary Supplement. Section 3 Anthropometry. Research Centre for Gender, Health \& Ageing. University of Newcastle. http://www.alswh.org.au/forresearchers/data.

Antufermo M, Di Meglio E (2012) Population and social conditions Eurostat: Statistics in Focus:1 - 8

Begarie J, Maiano C, Leconte P, Ninot G (2013) The prevalence and determinants of overweight and obesity among French youths and adults with intellectual disabilities attending special education schools. Res Dev Disabil 34:1417-1425 doi:10.1016/j.ridd.2012.12.007

Bergström H, Hagströmer M, Hagberg J, Schafer Elinder L (2013) A multi-component universal intervention to improve diet and physical activity among adults with intellectual disabilities in community residences: A cluster randomised controlled trial. Res Dev Disabil 34:3847-3857. doi:10.1016/j.ridd.2013.07.019

Bhaumik S, Watson JM, Thorp CF, Tyrer F, McGrother CW (2008) Body mass index in adults with intellectual disability: Distribution, associations and service implications: A population-based prevalence study. J Intellect Disabil Res 52:287-298.

Bigby C (2012) Social inclusion and people with intellectual disability and challenging behaviour: A systematic review. Int J Dev Disabil 37:360-374. doi:10.3109/13668250.2012.721878

Black RE, Morris SS, Bryce J (2003) Where and why are 10 million children dying every year? The Lancet 361:2226-2234. doi:http://dx.doi.org/10.1016/S0140-6736(03)13779-8

Braithwaite J, Mont D (2009) Disability and poverty: A survey of World Bank poverty assessments and implications. ALTER, Eur J Dis Research 3:219-232.

Cole TJ, Bellizzi MC, Flegal KM, Dietz WH (2000) Establishing a standard definition for child overweight and obesity worldwide: International survey. BMJ 320:1240-1243. 
Poverty and social exclusion and weight status

354 Cole TJ, Flegal KM, Nicholls D, Jackson AA (2007) Body mass index cut offs to define thinness in 355 children and adolescents: International survey. BMJ 335:194-202.

$356 \quad$ doi: $10.1136 / \mathrm{bmj} .39238 .399444 .55$

357 de Winter CF, Bastiaanse LP, Hilgenkamp TIM, Evenhuis HM, Echteld MA (2012) Overweight and

358 obesity in older people with intellectual disability. Res Dev Disabil 33:398-405.

359 doi:10.1016/j.ridd.2011.09.022

360 Emerson E (2007) Poverty and people with intellectual disabilities. Ment Retard Dev Disabil Res Rev

$361 \quad 13: 107-113$.

362 European Commission (2010) Communication from the Commission Europe 2020. A strategy for smart, 363 sustainable and inclusive growth. .35

364 Eurostat (2016a) Eurostat statistics explained. http://ec.europa.eu/eurostat/statistics-

365 explained/index.php/Europe in figures - Eurostat yearbook.

366 Eurostat (2016b) Eurostat statistics explained. People at risk of poverty or social exclusion. http://ec.europa.eu/eurostat/statisticsexplained/index.php/People at risk of poverty_or_social_exclusion. Accessed May 102016

Eurostat (2016c) Glossary: At risk of poverty or social exclusion (AROPE).

http://ec.europa.eu/eurostat/statisticsexplained/index.php/Glossary:At_risk_of_poverty_or_social_exclusion_(AROPE). Accessed May 112016

Gazizova D, Puri BK, Singh I, Dhaliwal R (2012) The overweight: Obesity and plasma lipids in adults with intellectual disability and mental illness. J Intellect Disabil Res 56:895-901. doi:10.1111/j.1365-2788.2011.01468.x obesity in childhood: The six-Cs model. Child Dev Perspect 5:50-58. doi:10.1111/j.17508606.2010.00150.x 
Poverty and social exclusion and weight status

379

380

381

382

383

384

385

386

387

388

389

390

391

392

393

394

395

396

397

398

399

400

401

402

403

Hsu SW, Yen CF, Hung WJ, Lin LP, Wu CL, Lin JD (2012) The risk of metabolic syndrome among institutionalized adults with intellectual disabilities. Res Dev Disabil 33:615-620. doi:10.1016/j.ridd.2011.09.005

Lloyd M, Foley JT, Temple VA (2014) Body mass index of children and youth with an intellectual disability by country economic status. Prev Med 69:197-201. doi:http://dx.doi.org/10.1016/j.ypmed.2014.10.010

Lloyd M, Temple VA, Foley JT (2012) International BMI comparison of children and youth with intellectual disabilities participating in Special Olympics. Res Dev Disabil 33:1708-1714. doi:10.1016/j.ridd.2012.04.014

McGrath L, Jones RSP, Hastings RP (2010) Outcomes of anti-bullying intervention for adults with intellectual disabilities. Res Dev Disabil 31:376-380. doi:http://dx.doi.org/10.1016/j.ridd.2009.10.006

Melville CA, Cooper SA, Morrison J, Allan L, Smiley E, Williamson A (2008) The prevalence and determinants of obesity in adults with intellectual disabilities. J Appl Res Intellect Dis 21:425437.

Mouridsen SE, Rich B, Isager T (2002) Body mass index in male and female children with infantile autism. Autism 6:197-205.

$\mathrm{Ng}$ M et al. (2014) Global, regional, and national prevalence of overweight and obesity in children and adults during 1980-2013: A systematic analysis for the Global Burden of Disease Study 2013. Lancet 384:766-781. doi:10.1016/s0140-6736(14)60460-8

Nota L, Ferrari L, Soresi S, Wehmeyer M (2007) Self-determination, social abilities and the quality of life of people with intellectual disability. J Intellect Disabil Res 51:850-865. doi:10.1111/j.13652788.2006.00939.x

Persoskie A, Ferrer RA (2017) A most odd ratio: Interpreting and describing odds ratios Am J Prev Med 52:224-228 doi:10.1016/j.amepre.2016.07.030 
Poverty and social exclusion and weight status

404 Prospective Studies Collaboration (2009) Body-mass index and cause-specific mortality in 900000

405

406

407

408

409

410

411

412

413

414

415

416

417

418

419

420

421

422

423

424

425

426

427

428

adults: Collaborative analyses of 57 prospective studies. Lancet 373:1083-1096.

doi:10.1016/S0140-6736(09)60318-4

Sari HY, Bahceci B (2012) Nutritional status of children with an intellectual disability. Int J Disabil Hum Dev 11:17-21.

Schalock RL (2011) The evolving understanding of the construct of intellectual disability. Int J Dev Disabil 36:227-237. doi:10.3109/13668250.2011.624087

Simmonds M et al. (2015) The use of measures of obesity in childhood for predicting obesity and the development of obesity-related diseases in adulthood: A systematic review and meta-analysis. Health Technol Assess 19:1-336. doi:10.3310/hta19430

Sohler N, Lubetkin E, Levy J, Soghomonian C, Rimmerman A (2009) Factors associated with obesity and coronary heart disease in people with intellectual disabilities. Soc Work Health Care 48:76 89.

Soler Marín A, Xandri Graupera J (2011) Nutritional status of intellectual disabled persons with Down syndrome. Nutrición Hospitalaria 26:1059-1066. doi:10.1590/S0212-16112011000500021

Special Olympics (2007) Healthy choices, healthy athletes: Health promotion guide for Clinical Directors. Special Olympics, Washington, DC

Special Olympics (2016) Special Olympics global strategic plan 2016 - 2020. Washington, DC

Temple VA, Foley JT, Lloyd M (2013) Body mass index of adults with intellectual disability participating in Special Olympics by world region. J Intellect Disabil Res 58:277-284 doi:10.1111/jir.12011

Temple VA, Foley JT, Lloyd M (2015) Body Mass Index of adult Special Olympians by country economic status. J Policy Pract Intellect Disabil 12:235-243. doi:10.1111/jppi.12123

Vidmar S, Carlin J, Hesketh K, Cole T (2004) Standardizing anthropometric measures in children and adolescents with new functions for egen. Stata Journal 4:50-55. 
Poverty and social exclusion and weight status

429 Weitoft GR, Eliasson M, Rosén M (2008) Underweight, overweight and obesity as risk factors for 430 mortality and hospitalization. Scand J Public Health 36:169-176.

431 doi:10.1177/1403494807085065

432 World Health Organization (1995) Physical status: The use and interpretation of anthropometry.

433 (Technical Report Series No. 854). World Health Organization, Geneva

434

435 
Poverty and social exclusion and weight status

436 